\title{
Asthma self-management programmes in a population of Italian children: a multicentric study
}

\author{
R. Ronchetti*, L. Indinnimeo*, E. Bonci*, A. Corrias**, D. Evans+, \\ M. Hindi-Alexander++, F. Midulla*, R. Pulejo\#, M.P. Villa* and the \\ Italian Study Group on Asthma Self-Management Programmes
}

Asthma self-management programmes in a population of Italian children: a multicentric study. R. Ronchetti, L. Indinnimeo, E. Bonci, A. Corrias, D. Evans, M. HindiAlexander, F. Midulla, R. Pulejo, M.P. Villa and the Italian Study Group on Asthma Self-Management Programmes. (CERS Journals Ltd 1997.

ABSTRACT: This study was designed to answer three main questions: 1) Does asthma self-management education reduce asthma morbidity? 2) Are the two programmes "Living With Asthma" and "Open Airways" equally effective in doing so? 3) Is a shortened version of these programmes (4 weeks) as effective as the longer original programme $(8$ weeks)?

Twelve Italian centres of paediatric bronchopneumology selected 312 children with asthma, who were stratified by disease severity, gender and age, and then randomly assigned to an Experimental group which received an educational programme or to a Comparison group, which did not. Of the 312 children selected, 209 (114 Experimental and 95 Comparison) completed the educational protocol and a 1 year follow-up.

Data recorded during the last 2 months of follow-up, 10 months after the educational intervention, showed that the Experimental group required significantly fewer emergency treatments: this reduction was more evident in the more severe asthma cases. In the Experimental, but not in the Comparison group, patients with more severe asthma consumed more medications than patients with milder asthma. "Open Airways" yielded, in some cases, better results than "Living with Asthma": but a type 2 error is possible. The standard and the shortened programmes proved equally effective.

In conclusion, following education, regardless of receiving a short or long educational programme, asthma patients use emergency care services less and use medications more appropriately in comparison with standard care without education. This suggests that short educational programmes can be highly cost-effective in children with asthma.

Eur Respir J 1997; 10: 1248-1253
*Dept of Pediatrics, University "La Sapienza", Rome, Italy. **Dept of Pediatrics, University of Cagliari, Cagliari, Italy. ${ }^{+}$Columbia University, New York, USA. ++National Institutes of Health, Bethesda, USA. "Casa del Sole Hosp., Palermo, Italy.

Correspondence: R. Ronchetti IV Cattedra di Clinica Pediatrica Universita' degli Studi di Roma

"La Sapienza"

Viale Regina Elena 324

00161 Roma

Italy

Keywords: Asthma education

asthma in children

asthma medication

asthma self-management

emergency room utilization

Received: June 201996

Accepted after revision January 141997

Supported in part by grants from the Progetto Finalizzato Medicina Preventiva, Subprogetto Medicina Perinatale, Consiglio Nazionale delle Ricerche (CNR), Italy and by travel grants from the National Heart, Lung, and Blood Institute NIH, Bethesda, USA.
There has been ample evidence to show that health education programmes can reduce morbidity and health care costs $[1,2]$, and possibly improve the quality of life for persons with asthma [1,3-6]. However, the majority of physicians have not adopted asthma education programmes as a regular part of routine asthma care [7]. One reason is that asthma education programmes are time-consuming, difficult to set-up, and not easily reimbursed. It is also hard for an interested clinician to choose one programme from the many proposed. These difficulties prompted the Italian Pediatric Working Group for Respiratory Diseases to test, in a large trial (Project Italia), the effectiveness of an educational intervention (given in the form of self-management courses) in reducing childhood asthma morbidity. Concurrently, it was decided to test two subordinate hypotheses: whether the two well-known programmes "Living with Asthma" (LwA) [8] and "Open Airways" (OA) [9], though originally intended for distinct target populations, would each be similarly effective in reducing asthma morbidity; and whether shortening the two programmes from the original seven or eight sessions, respectively, to four sessions each, would reduce their cost, without diminishing their effectiveness.

Before the trial started, the Respiratory Service of the Pediatric Department of the University "La Sapienza", Rome, conducted two pilot studies. The findings have been published in a preliminary report [10]. The initial pilot study recruited 20 families from the out-patient clinic. It achieved a high rate of family attendance, and

Italian Study Group on Asthma Self-Management Programmes: University Departments of Pediatrics: L. Armenio, L. Spadaveechia (Bari); G. Baldini, R. Bonfanti (Pisa); A. Barbato, S. Zanconato (Padova); A. Battistini, P.L. Grzincich (Parma); A. Boner, C. Castellani (Verona); A. Corrias, G. Rossi (Cagliari); E. Novembre, C. Azzari (Firenze); L. Indinnimeo, F. Macri (Roma); M. La Rosa, C. Ranno (Catania); M. Miraglia Del Giudice Jr., F. Decimo (Napoli); M.P. Villa, F. Bernardi (Bologna).

Hospitals: D. Castello, C. Robusto (Osp. Inf. Regina Margherita, Torino); R. Pulcjo, S. La Grutta (Osp. Casa del Sole, Palermo). 
the programmes significantly increased the participants' understanding of asthma. The second pilot study, conducted on school children of Atri and Viterbo, two rural regions of Italy [10], underlined the formidable difficulties in enrolling families into health education programmes in field-based studies. For this reason, we decided to conduct our trial with a design based on medical centres specialized in the care of paediatric asthma.

In this paper, we present the research design of Project Italia and discuss the results for the above three hypotheses.

\section{Materials and methods}

\section{Selected programmes}

Both asthma education programmes provided once weekly $1 \mathrm{~h}$ sessions, to be held separately for parents and children, in groups of 10 . The original eight sessions for LwA and seven sessions for OA were equalized to eight sessions for both programmes in Phase I, and to four sessions in Phase II (see below).

Both programmes share information on certain basic items concerning: the anatomy of the lungs; the pathophysiology of asthma; the trigger factors; and the warning signs and symptoms of asthma attacks. They explain how to deal with attacks, how to rationalize use of emergency rooms, and how to reduce the social consequences of asthma (for example, its effect on sport, school and personal relationships).

Both programmes recognize that children and families should take on more responsibility for managing their asthma; and they also emphasize how important it is that parents and physicians co-operate. However, their teaching strategies differ. LwA has a group format and makes extensive use of written diaries for responding to problems and, to develop asthma management skills, it requires a high level of literacy skills. Although originally developed for a rural population, it can be used in medical care and community settings. OA uses an educational approach that encourages group members to share their problems and develop solutions together. It aims to ensure that barriers to management are identified, that solutions are practical, and that both parent and child feel capable of carrying them out. Like LwA, the OA programme can be used in medical care and community settings [11].

During Phase II, the two programmes were shortened from eight to four sessions. None of the programme items were left out, but each item was condensed so that the course could be completed in four sessions.

\section{Research design}

To avoid bias from potential sociocultural differences, the original design called for 14 centres stratified into three areas: northern, central, and southern Italy. Within these blocks, each centre was randomly assigned to one of the two programmes: OA or LwA.

In Phase I, each centre had to enrol a number of families (the target being 20), randomly allocating an equal number to the Experimental group, who received the complete version of the assigned programme, and to the Comparison group, who continued standard asthma care without an education programme. In Phase II, they enrolled a further group of families whom they randomly allocated as before, except that the Experimental group received the four session, shortened version of the assigned programme. This procedure yielded a sample of families divided equally between Experimental and Comparison groups.

Two centres who did not follow the protocol and did not obtain the required baseline information dropped out of the collaborative study. Of the 12 centres that did participate, seven had been randomly programmed to deliver the OA programme and five to deliver the LwA programme. The 12 centres enrolled a total of 312 patients in the study.

\section{Methods}

Except for two centres (one using a psychologist and a physician, and the other a social worker and a physician), most centres selected two physicians to co-ordinate and conduct the research activities. All the selected researchers met in Rome for a 3 day seminar to introduce the concept and explore the aims of the project. Previous experiences with the delivery of programmes of asthma education were presented and discussed. This was followed by specific training regarding the design and methodology of the study. To ensure a blind procedure, the protocol required the physicians delivering the educational programmes to be different from those responsible for the medical management of the participants during the follow-up period. The Respiratory Service of the Pediatric Department of the University "La Sapienza" in Rome also acted as the co-ordinating and data management centre for Project Italia.

All of the 12 centres assessed baseline morbidity variables between April and May.

\section{Entry criteria}

Eligible children were out-patients attending the asthma clinic, who were seen for the first time, and who received a diagnosis of asthma. The diagnosis was established in accordance with standards of the American Thoracic Society (ATS) [12].

At enrolment, the parents completed a questionnaire designed to collect morbidity data on the number of asthma attacks, hospitalizations and emergency treatments for asthma during the previous 12 months. A one page diary eliciting the same information plus the amount of medicine consumed was then completed, prospectively, on a weekly basis during a 1-3 week baseline period that preceded the educational programme (Pre). It had previously been established that, during the baseline period, each child, if symptomatic, would receive a $\beta_{2}$ short-acting drug plus beclomethasone dipropionate four times a day, with the addition of theophylline and/or oral corticosteroids if seriously ill. The same information was gathered during a 2 month period, 11 and 12 months after the programme (Post): at this time, however, the diary reported the treatment freely prescribed 
by the treating physicians. Once enrolled, each group of 20 children was stratified by asthma severity (a composite score explained below), gender and age, and then randomly assigned within strata, to the Experimental or Comparison group. This procedure was intended to provide balanced, if not matched, groups for study.

\section{Variables and asthma "severity score"}

This paper presents data on the "severity score" determined from the following five asthma morbidity variables: 1) forced expiratory volume in one second (FEV1) (as percentage of predicted value) as measured at enrolment; 2) number and amount of medications used during the baseline period (number of drugs $\times$ daily doses $\times$ days); 3 ) number of asthma attacks; 4) number of hospitalizations; and 5) number of emergency treatments (variables 3, 4 and 5 relative to the preceding 12 months).

FEV1 was collected with commercially available electronic spirometric equipment, calibrated by syringe for volumes. Preintervention values were adjusted to make them comparable to the 2 month period covered in the follow-up (i.e. the yearly baseline estimates of morbidity were divided by 6 , and the number of medications per week recorded at baseline was multiplied to equal 8 weeks). The severity levels of asthma at enrolment were based on the five variables above, with severity scores ranging 5-15 (table 1). The same five variables were used at the follow-up to measure the results 11-12 months after the educational programmes.

\section{Statistical analysis}

The data were analysed for significance with Statistical Package for the Social Sciences (SPSS)-PC software. The square root transformation was applied to hospitalization and emergency treatments to equalize the variances. Statistical analyses, as appropriate, in baseline and post-course were performed on transformed data.

Table 1. - Asthma severity score recorded at enrolment

\begin{tabular}{lccc}
\hline & \multicolumn{3}{c}{ Score levels* } \\
Variables & 1 & 2 & 3 \\
\hline $\begin{array}{l}\text { FEV1 \% pred } \\
\begin{array}{l}\text { Asthma attacks in the } \\
\text { preceding year }\end{array}\end{array}$ & 2 & $30-80$ & $<70 \%$ \\
$\begin{array}{l}\text { Hospitalizations in the } \\
\text { preceding year }\end{array}$ & 0 & $1-2$ & $>2$ \\
$\begin{array}{l}\text { Emergency treatments in the } \\
\text { preceding year }\end{array}$ & $0-2$ & $3-6$ & $>6$ \\
$\begin{array}{l}\text { Medications taken during the } \\
\text { 1-3 week baseline observation } \\
\text { period }\end{array}$ & $0-4$ & $5-15$ & $>15$ \\
\end{tabular}

*: each of the five variables had three score levels, allowing the overall score to range 5-15. An arbitrary decision was made to define the severity levels, according to the following scores: mild 5-7; moderate 8-10; severe 11-15. FEV1: forced expiratory volume in one second; \% pred: percentage of predicted value.
The lack of a significant influence of the multicentric design of the study on results was assessed by means of multiple regression analysis, each centre being considered an independent variable. The differences between the morbidity variables recorded at the 2 month followup in the Experimental and Comparison groups were evaluated with analysis of covariance (ANCOVA), controlling for baseline values. Spearman's correlation was used to study the correlation between severity and medications taken. A p-value of less than 0.05 was considered significant.

\section{Results}

\section{Enrolment}

The 12 centres initially succeeded in enrolling 312 participants (Experimental + Comparison). Of the 114 patients in the Experimental group, 106 attended at least $75 \%$ of the educational sessions. To control for bias from seasonal variations, the follow-up took place in April and May, as did baseline assessment. To reinforce adherence at follow-up, a letter was sent to all patients in the study. This achieved participation at the followup by 209 subjects, subdivided into 114 Experimental and 95 Comparison group patients. Our analysis takes into account data concerning this follow-up, adjusted for baseline differences.

\section{Baseline comparability}

No statistically significant differences in gender, age and asthma severity were evident between children who completed the study and those who did not attend the 11-12 months follow-up (table 2).

The baseline comparability of Experimental and Comparison subjects who attended the follow-up, subdivided into groups of programmes (LwA vs OA) and Phases (8 sessions vs 4 sessions) was established by examining the stratifying variables (table 3 ). No significant differences emerged between groups (Experimental and Comparison overall or subdivided into Programmes and Phases) for ages, for the five morbidity variables or for the severity score of asthma. The mean severity score ranged 7.2-7.5 (table 3 ).

\section{Comparability at follow-up}

The follow-up, 11-12 months after the end of the educational programmes, showed few, but important, differences between the Experimental and Comparison groups. A multiple regression analysis evaluating each centre as an independent variable showed that none of these differences depended on the multicentric design. Overall, the results showed that the Experimental group had significantly fewer emergency treatments $(p<0.05)$ than the Comparison group (table 4). The OA Experimental group needed significantly fewer emergency treatments than their Comparison group $(\mathrm{p}<0.03)$. In the LwA group, 
Table 2. - Baseline comparability of in-study subjects and drop-outs at the last follow-up

\begin{tabular}{|c|c|c|c|c|c|c|}
\hline & \multicolumn{3}{|c|}{ Experimental group } & \multicolumn{3}{|c|}{ Comparison group } \\
\hline & $\begin{array}{l}\text { In-study } \\
(n=114)\end{array}$ & $\begin{array}{l}\text { Drop-outs } \\
\quad(n=48)\end{array}$ & p-value & $\begin{array}{l}\text { In study } \\
(n=95)\end{array}$ & $\begin{array}{l}\text { Drop-outs } \\
\quad(n=55)\end{array}$ & p-value \\
\hline Gender $\mathrm{M} / \mathrm{F} \%$ & $68 / 32$ & $66 / 34$ & NS & $61 / 39$ & $59 / 41$ & NS \\
\hline Age yrs $\#$ & $9.4 \pm 0.2$ & $9.5 \pm 0.2$ & NS & $9.9 \pm 0.2$ & $9.4 \pm 0.2$ & NS \\
\hline Asthma severity score & $7.4 \pm 0.2$ & $7.2 \pm 0.2$ & NS & $7.4 \pm 0.2$ & $7.0 \pm 0.2$ & NS \\
\hline
\end{tabular}

\#: mean士sEM. NS: nonsignificant.

Table 3. - Comparability of the eight in-study groups at baseline

\begin{tabular}{|c|c|c|c|c|c|c|c|c|c|c|c|}
\hline & \multicolumn{4}{|c|}{ Programme } & \multicolumn{4}{|c|}{ Length of programme } & \multicolumn{2}{|c|}{ Subtotal } & \multirow[t]{3}{*}{ Total } \\
\hline & \multicolumn{2}{|r|}{ LwA } & \multicolumn{2}{|r|}{ OA } & \multicolumn{2}{|c|}{ Phase I } & \multicolumn{2}{|c|}{ Phase II } & \multirow[b]{2}{*}{$\mathrm{E}$} & \multirow[b]{2}{*}{$\mathrm{C}$} & \\
\hline & $\mathrm{E}$ & $\mathrm{C}$ & $\mathrm{E}$ & $\mathrm{C}$ & E & $\mathrm{C}$ & $\mathrm{E}$ & $\mathrm{C}$ & & & \\
\hline Subjects $n$ & 40 & 28 & 74 & 67 & 58 & 56 & 56 & 39 & 114 & 95 & 209 \\
\hline Gender $\%$ males & 62 & 64 & 70 & 60 & 62 & 62 & 73 & 59 & 68 & 61 & 65 \\
\hline \multirow[t]{3}{*}{ Age yrs } & 9.4 & 9.7 & 9.4 & 9.9 & 9.2 & 9.6 & 9.6 & 10.2 & 9.4 & 9.9 & 9.6 \\
\hline & \pm 0.3 & \pm 0.3 & \pm 0.2 & \pm 0.2 & \pm 0.2 & \pm 0.3 & \pm 0.3 & \pm 0.3 & \pm 0.1 & \pm 0.1 & \pm 0.1 \\
\hline & $7-13)$ & $(7-13)$ & $(6-13)$ & $(7-14)$ & $(7-13)$ & $(7-14)$ & $6-13)$ & $(7-14)$ & 6-13) & $(7-14)$ & $6-14)$ \\
\hline \multirow{2}{*}{ FEV1 $\%$ pred } & 93 & 96 & 89 & 92 & 92 & 94 & 89 & 90 & 91 & 93 & 92 \\
\hline & \pm 4 & \pm 3 & \pm 2 & \pm 2 & \pm 2 & \pm 3 & \pm 3 & \pm 2 & \pm 2 & \pm 2 & \pm 1 \\
\hline \multirow[t]{2}{*}{ Asthma attacks n } & 0.7 & 0.7 & 0.6 & 0.7 & 0.7 & 0.7 & 0.6 & 0.7 & 0.6 & 0.7 & 0.7 \\
\hline & \pm 0.1 & \pm 0.1 & \pm 0.1 & \pm 0.1 & \pm 0.1 & \pm 0.1 & \pm 0.1 & \pm 0.1 & \pm 0.1 & \pm 0.1 & \pm 0.1 \\
\hline \multirow[t]{2}{*}{ Hospitalizations $\mathrm{n}$} & 0.04 & 0.09 & 0.05 & 0.02 & 0.05 & 0.04 & 0.04 & 0.02 & 0.04 & 0.03 & 0.04 \\
\hline & \pm 0.01 & \pm 0.02 & \pm 0.01 & \pm 0.01 & \pm 0.01 & \pm 0.01 & \pm 0.01 & \pm 0.01 & \pm 0.01 & \pm 0.01 & \pm 0.01 \\
\hline Emergency & 0.31 & 0.22 & 0.21 & 0.22 & 0.32 & 0.21 & 0.23 & 0.21 & 0.25 & 0.17 & 0.21 \\
\hline treatments $\mathrm{n}$ & \pm 0.03 & \pm 0.03 & \pm 0.03 & \pm 0.04 & \pm 0.05 & \pm 0.03 & \pm 0.04 & \pm 0.05 & \pm 0.03 & \pm 0.03 & \pm 0.02 \\
\hline Medications & 42.0 & 52.8 & 63.9 & 53.3 & 52.7 & 54.3 & 59.0 & 50.4 & 55.3 & 53.1 & 54.4 \\
\hline taken $\mathrm{n}$ & \pm 7.5 & \pm 5.6 & \pm 6.4 & \pm 7.0 & \pm 7.1 & \pm 7.6 & \pm 6.9 & \pm 7.3 & \pm 4.0 & \pm 5.1 & \pm 3.7 \\
\hline \multirow[t]{2}{*}{ Severity score } & 7.5 & 7.5 & 7.3 & 7.4 & 7.4 & 7.4 & 7.2 & 7.5 & 7.4 & 7.4 & 7.4 \\
\hline & \pm 0.3 & \pm 0.9 & \pm 0.2 & \pm 0.2 & \pm 0.2 & \pm 0.2 & \pm 0.2 & \pm 0.2 & \pm 0.2 & \pm 0.2 & \pm 0.1 \\
\hline
\end{tabular}

Values are presented as mean \pm SEM, and range in parenthesis. Numbers of asthma attacks, hospitalizations and emergency treatments represent the mean numbers of events per patient per two months, derived from information collected during the baseline period. Medications taken: number and amount of medications used during the baseline period (number of drugs $\times$ daily doses $\times$ days); Phase I: 8 sessions; Phase II: 4 sessions; FEV1: forced expiratory volume in one second; $\%$ pred: percentage of predicted value; LwA: Living with Asthma; OA: Open Airways. No significant differences were found between Experimental (E) and Comparison $(\mathrm{C})$ groups.

Table 4. - Emergency treatments during the two month follow-up in mild, moderate and severe asthma cases in Experimental (E) and Comparison (C) groups

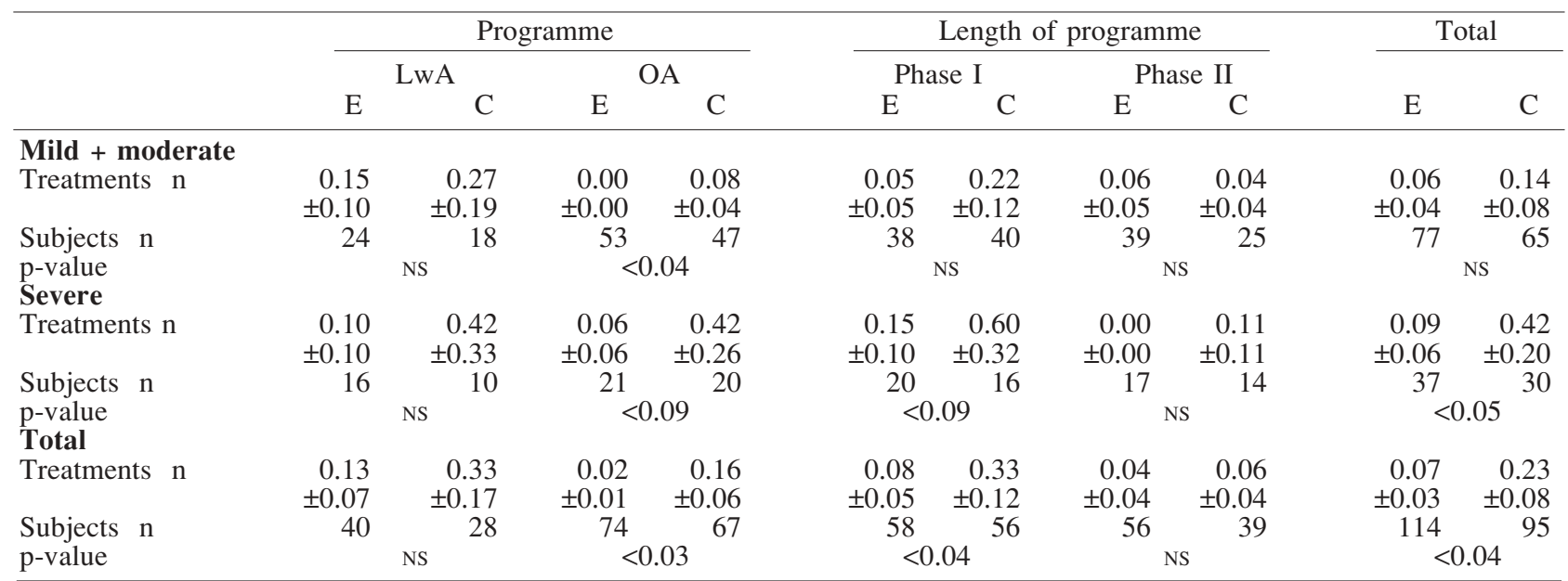

Data represent the mean \pm SEM number of emergency treatments per patient, observed during the 2 month follow-up period. Severity of asthma was derived from the "severity score" assessed at the baseline period. Phase I: 8 sessions; Phase II: 4 sessions; LwA: Living with Asthma; OA: Open Airways; ns: nonsignificant.

this difference did not reach statistical significance. Emergency treatments differed in Phase I (the full programme) $(\mathrm{p}<0.04)$ but not in Phase II (the shortened programme).

Stratification of the children studied into two levels of asthma severity, according to baseline information (table 4), showed that the difference in emergency treat- ments between Experimental and Comparison groups arose mainly from patients with the most severe asthma. During the follow-up period, these more severe Comparison children required emergency treatment five times more frequently than similar patients in the Experimental group $(\mathrm{p}<0.05)$. 
Table 5. - Medications taken during the two month follow-up in mild, moderate and severe asthma cases in Experimental (E) and Comparison (C) groups

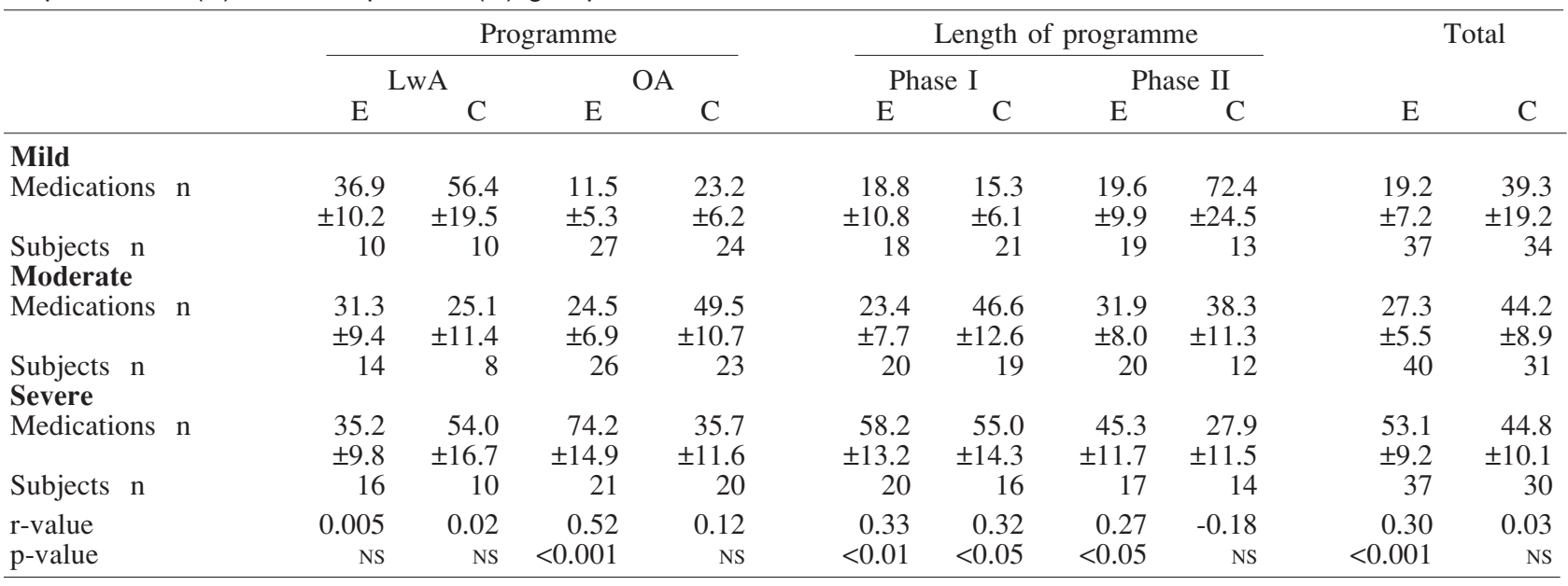

Data represent the mean \pm SEM number of medications (short-acting $\beta_{2}$, beclomethasone dipropionate, theophylline and oral corticosteroids; number of drugs $\times$ daily doses $\times$ days) prescribed by treating physicians during the follow-up. LwA: Living with Asthma; OA: Open Airways; Phase I: 8 sessions; Phase II: 4 sessions; ns: nonsignificant.

The comparison between asthma severity scores assessed at baseline (before the courses) and the number of medications taken during the 2 month follow-up showed that Experimental group children with severe asthma consumed more medications than those with milder forms of the illness (table 5). In the Comparison group, the severity of the disease did not correlate with the number of medications taken during the follow-up (patients with milder asthma took as many drugs as the more severe patients).

A similarly significant correlation between severity of asthma and the consumption of medications emerged in the OA and in Phase I or Phase II Experimental cases, but not in the LwA Experimental cases.

\section{Discussion}

Our findings show that an educational intervention, such as the one administered to the Experimental population, significantly reduces the number of emergency treatments required for children with asthma. This finding confirms the results of several previous studies showing that most asthma self-management programmes reduce the number of emergency treatments, together with days of hospitalization $[1,2,4,13,14]$ or school absences for asthma [15].

In the present study, we provided evidence that these changes still existed 11-12 months after the educational course. In agreement with other studies, when we stratified our cases by severity of asthma, we found that the number of emergency treatments had decreased mainly in subjects in the Experimental group suffering from more severe disease $[1,15]$. Our results also showed that in the Experimental group, the children with severe disease used more medications than those with mild asthma, a difference that did not emerge between severe and mild cases in the Comparison group.

The results presented in this paper show that an asthma education programme modifies and improves the behaviour and, presumably, the self-confidence of the family for at least $1 \mathrm{yr}$. Because none of our evalua- tions revealed a change in either of the two objective variables, namely the number of attacks and FEV1, we cannot conclude that we observed a real change in clinical severity of the illness $[16,17]$. Nonetheless, the evident changes in our patients' use of medical facilities, such as the emergency room and medication, show a more "rational" family behaviour, one of the most desirable goals of any educational programme.

Interestingly, during follow-up visits, some patients expressed ideas on the illness and on its treatment, showing that they had oversimplified the therapeutic suggestions given during the course. This led us to conclude that an educational programme cannot be designed only to improve patients' knowledge about regular and emergency asthma management [18-20]. It should always be envisaged as a continual process that becomes a regular part of asthma care. We fully agree with recent reports that recommend scheduling asthma education programmes for each of the follow-up visits [21]. This procedure allows the physician to check whether the principles taught have been understood and applied correctly.

In formulating our second hypothesis, that $\mathrm{OA}$ and LwA would produce similar clinical results, we intended to check whether the results depended more on the fact that an asthma self-management course had been administered or on the specific philosophy of the course used. One event that might have influenced our results is that, unfortunately, the two centres eliminated early on were both assigned to LwA, thus reducing the number of cases receiving this course and the statistical power of the analysis. This may explain why OA decreased emergency treatments significantly, whereas LwA decreased them in the same direction without reaching statistical significance, suggesting the possibility of a type 2 error (table 4 ).

Similarly, in patients who received OA, but not in those who had LwA, we found a significant correlation between scores of severity of asthma and consumption of medications (table 5). Our results, therefore, indicate that when applied in a homogeneous urban middle-class population of asthmatics, such as the one we studied, 
both the programmes tend to alter the utilization of emergency rooms and medications. Because both programmes provide a wide range of information about asthma and the psychological dynamics of the families of asthmatic children, other studies investigating different populations or analysing outcomes unlike those considered here, may reach different conclusions about the two courses.

In evaluating the third hypothesis, we compared the results of Phase I (courses given in eight sessions) with those of Phase II (duration halved to four sessions). In Phase I, the results showed that emergency treatments differed significantly in Experimental and Comparison groups: they did not differ significantly in Phase II in which the events were very rare (table 4). The analysis of the appropriateness of drug consumption to the severity of the illness showed a significant difference between "educated" and Comparison subjects both in Phase I and in Phase II: Experimental groups invariably consumed an amount of medication more appropriate to the severity of asthma. In conclusion, our study suggests that, for the routine care of children with asthma, good results could be obtained with less effort and with shorter courses than those originally proposed.

A precise analysis of cost-effectiveness was beyond the scope of the present paper, but preliminary calculations based on our data suggest a fivefold saving when comparing the expenses for setting up the courses with the reduction in the use of the medical resources. This advantage could be even greater if the shorter versions of the courses are used. However, we believe that the most advantageous ratio between the length of the educational programme and its efficacy in improving the control of asthma remains uncertain [22].

A large trial, such as Project Italia, has an outcome that is difficult to measure yet undeniably valuable: the trial engendered a widespread exchange of ideas that surely helped to modify the attitudes and behaviours of participating families and physicians alike. We consider this experience to be of primary importance in designing a better educational strategy, that will improve the quality of care for children with asthma.

\section{References}

1. Clark NM, Feldman CH, Evans D, Levison MJ Wasilewski Y, Mellins RB. The impact of health education on frequency and cost of health care use by low income children with asthma. J Allergy Clin Immunol 1986; 78: 108-115.

2. Lewis CE, Rachelefsky G, Lewis MA, De La Sota A, Kaplan M. A randomized trial of ACT (asthma care training) for kids. Pediatrics 1984; 74: 478-486.

3. Evans D, Clark NM, Feldman CH. A school health education program for children with asthma aged 8-11 years. Health Educ Q 1987; 14: 267-280.

4. Hindi-Alexander M, Cropp GJA. Evaluation of a fam- ily asthma program. J Allergy Clin Immunol 1984; 74: 505-510.

5. Hindi-Alexander M, Throm J, Middleton E Jr. Collaborative asthma self-management: evaluation designs. Clin Rev Allergy 1987; 5(3): 249-258.

6. Wilson-Pessano SR, McNabb W. The role of patient education in the management of childhood asthma. Prev Med 1985; 14: 670-687.

7. Parker SR, Mellins RB, Sogn DD. National Health, Lung and Blood Institute, Workshop Summary. Asthma education: a national strategy. Am Rev Respir Dis 1989; 140: 848-853.

8. National Heart, Lung and Blood Institute. Living with Asthma: Asthma Self-Management Program. 1984; NIH Publication No. 84-2364.

9. National Heart, Lung and Blood Institute. Open Airways/Respiro Albierto: Asthma Self-Management Program. 1984; NIH Publication No 84-2365.

10. Indinnimeo L, Midulla $\mathrm{F}$, Hindi-Alexander $\mathrm{M}$, et al. Controlled studies of childhood asthma self-management in Italy using the "Open Airways" and "Living with Asthma" programs: a preliminary report. Health Educ Q 1987; 14: 291-308.

11. Evans D, Mellins RB. Educational programs for children with asthma. Pediatrician 1991; 18: 317-321.

12. American Thoracic Society. Standards for the diagnosis and care of patients with chronic obstructive pulmonary disease (COPD) and asthma. Am Rev Respir Dis 1987; 136: 255-344.

13. Staudenmayer H, Harris PS, Seluer JC. Evaluation of a self education exercise program for asthmatic children and their parents: six month follow-up. J Asthma 1981; 18: $1-5$.

14. Toelle BG, Peat JK, Salome CM, et al. Evaluation of a community-based asthma management program in a population sample of schoolchildren. Med J Aust 1993; 46; 158-742.

15. Fireman P, Friday GA, Gira C, Vierthaier WA, Michaels L. Teaching self-management skills to asthmatic children and their parents in an ambulatory care setting. Pediatrics 1981; 68: 341-348.

16. Howland J, Bauchuex H, Adair R. The impact of pediatric asthma education: assessing the evidence. Chest 1988; 94: 964-969.

17. Creer TL, Wigal JK, Kotses H, Lewis P. A critique of 19 self-management programs for childhood asthma. Part II. Comments regarding the scientific merit of the programs. Pediatr Asthma Allergy Immunol 1990; 4: 41-55.

18. Sibbald B. Patient self-care in acute asthma. Thorax 1989; 44: 97-101.

19. Fletcher HJ, Ibrahim SA, Splight N. Survey of asthma deaths in the Northern region 1970-1985. Arch Dis Child 1990; 65: 163-167.

20. Silverman M. Self-management plans for asthma (Letter). Arch Dis Child 1990; 65: 333.

21. Boulet LP, Chapman KR, Green LW, Fitzgerald JM. Asthma Education. Chest 1994; 106 (Suppl. 4): 184S196S.

22. Wilson SR, Schneidkraut NS. State of art in asthma education: the US experience. Chest 1994; 106 (Suppl. 4): 197S-205S. 